\title{
BMJ Open Preparedness for peer first response to mining emergencies resulting in injuries: a cross-sectional study
}

\author{
Sofia Karlsson, ${ }^{1}$ Britt-Inger Saveman, ${ }^{1}$ Magnus Hultin (D) , ${ }^{2}$ Ulf Björnstig, ${ }^{1}$ \\ Lina Gyllencreutz ${ }^{1}$
}

To cite: Karlsson S,

Saveman B-I, Hultin M, et al. Preparedness for peer first response to mining emergencies resulting in injuries: a crosssectional study. BMJ Open 2020;10:e036094. doi:10.1136/ bmjopen-2019-036094

- Prepublication history for this paper is available online. To view these files, please visit the journal online (http://dx.doi. org/10.1136/bmjopen-2019036094).

Received 29 November 2019 Revised 03 August 2020 Accepted 22 September 2020

D) Check for updates

(C) Author(s) (or their employer(s)) 2020. Re-use permitted under CC BY-NC. No commercial re-use. See rights and permissions. Published by BMJ.

${ }^{1}$ Department of Surgical and Perioperative Sciences, Surgery, Umeå University, Umeå, Sweden ${ }^{2}$ Department of Surgical and Perioperative Sciences, Anesthesiology and Intensive Care Medicine, Umeå University, Umeå, Sweden

Correspondence to

Dr Magnus Hultin;

magnus.hultin@umu.se

\section{ABSTRACT}

Objective Identify factors of preparedness for peer first response to underground mining emergencies with injured victims.

Design Cross-sectional questionnaire study of Swedish underground mineworkers.

Setting Seven out of nine Swedish underground mines. Participants A total of 741 mineworkers out of 1022 (73\%) participated in this study.

Interventions None.

Outcome measures Level of preparedness for emergencies with injuries in underground mines.

Results Three factors influenced the preparedness of mineworkers for a peer first response: (1) familiarity with rescue procedures during emergencies with injuries;

(2) risk perception of emergencies with injuries and (3) experience of using self-protective and first aid equipment. Mineworkers who believed that they knew how to handle emergencies with injuries (OR 1.30, 95\% $\mathrm{Cl} 1.22$ to 1.38) and those who were trained in the use of self-protective and first aid equipment (OR 1.19, 95\% $\mathrm{Cl} 1.07$ to 1.32) considered themselves to be better prepared for a peer first response than those who were unfamiliar with the rescue procedures or who had not used self-protective and first aid equipment. However, mineworkers who rated the risk for emergencies with injuries as high considered themselves to be less prepared than those who rated the risk as low (OR $0.95,95 \% \mathrm{Cl} 0.91$ to 0.98$)$.

Conclusion This study identified three factors that were important for the peer-support preparedness of underground mineworkers. More research is needed to adapt and contextualise first aid courses to the needs of underground peer responders.

\section{INTRODUCTION}

Mining emergencies are infrequent occurrences but may result in severe consequences, such as the injury or death of mineworkers. ${ }^{12}$ Thus, mining emergencies require an efficient and timely response. ${ }^{3}$ According to an international literature review, ${ }^{4}$ most of the literature relates to incidents in coal mines. The organic nature of coal has a different set of risks than metalliferous mines. ${ }^{4}$ Thus, studying the Swedish setting, with its mineral and metalliferous

\section{Strengths and limitations of this study}

The study had a high response rate $(73 \%)$ and included participants from seven out of nine underground mines in Sweden.

- Exploratory factor analysis and multiple logistic regression analysis facilitated the identification of key factors associated with emergency medical preparedness.

- Postestimation tests of the multiple logistic regression model indicated a goodness of fit.

- The questionnaire was evaluated with a face validity test among experienced mineworkers, whereas a comprehensive pilot study may have improved the questionnaire, as would a test/retest or random response test.

- This study is based on data from the mineworkers' self-assessed level of preparedness; other methods, including knowledge test or observation of full-scale practical exercises, could have generated more objective responses.

underground mines, can contribute to the knowledge base of the scientific literature. The most common emergencies in mineral and metalliferous underground mines are fires, vehicular incidents and rock-falls. ${ }^{4} \mathrm{~A}$ major underground fire, for example, can lead to partially or temporarily sealed off areas, which means that mineworkers might have to self-evacuate or be rescued. ${ }^{5}$ Fires can influence the roof stability as well as generate toxic gases and create oxygen-depleted environments in large sections of the mine. ${ }^{2}$ This makes both self-initiated escape and rescue operations difficult. ${ }^{6}$ Mine rescue operations take time regardless of whether the company's own mine rescue teams undertake the rescue operations or the local rescue services and emergency medical service (EMS) ${ }^{78}$ The most common in Europe is for the mines to have their own rescue teams while the Swedish rely on the local services. ${ }^{7}$ To facilitate rescue operations, Swedish mines are required to either train their own mine rescue service or 
have mine guides to assist the local rescue service. ${ }^{9}$ Nonetheless, there is a delay as the rescue teams have to reach the remote mine, ${ }^{8}$ plan the rescue operation and navigate a complex environment to reach the incident site, which could be far underground. ${ }^{1011}$

Because time-consuming rescue operations can be fatal for severely injured victims, ${ }^{12}$ mineworkers in the vicinity of the injured need to act as immediate responders and care for their injured peers until professional help arrives. ${ }^{13}$ Immediate responders must have essential knowledge, skills and equipment ${ }^{14}$ in order to care for their injured peers. The combination of being a peer to the victim and being unskilled at handling injuries may lead to emotional distress that might impede their actions. $^{15}$

To escape or be rescued during emergencies, the Mine Safety Technology and Training Commission ${ }^{11}$ recommends that mineworkers should be trained in three key areas: (1) knowledge of escape/rescue technologies, (2) mine-specific knowledge in order to find evacuation routes and (3) escape/rescue conceptual knowledge to facilitate difficult decision making in an emergency situation. A lack of knowledge of mineworkers in these areas may have fatal consequences. For example, in the Sago mine explosion in $2006,{ }^{16} 12$ mineworkers died, and they lacked knowledge of how to use self-contained self-rescuers. ${ }^{17}$

Swedish mining companies aim to prevent and mitigate incidents by focusing on risk management, evacuation technology and escape routes. ${ }^{18}$ Moreover, the companies acknowledge the need for preparedness of their personnel for incidents and implement work-safety regulations, including those for first aid and psychological and social support after emergencies. ${ }^{19}$ These regulations are defined based on the type and risks of the workplace, and a sufficient number of workers need to be prepared to provide first aid, with adequate knowledge of and access to the relevant equipment needed for first aid. ${ }^{19}$ Thus, preparedness to respond to incidents is an essential element of any underground mine's strategic plan. ${ }^{20}$ However, there are few studies in the literature on the medical aspects and peer first response in mining emergencies with injuries. ${ }^{4}$ By studying the preparedness of Swedish mineworkers for emergencies with injuries, the complementing factors in the above-described three key areas can be identified.

Thus, this study aimed to identify factors of preparedness for peer first response to underground mining emergencies with injured victims. A secondary objective was to describe the preparedness of Swedish mineworkers, which is the data the factors are identified from.

\section{METHODS}

Design

This study was a national cross-sectional questionnaire survey.
Table 1 Characteristics of the mineworkers included in this study

\begin{tabular}{ll}
\hline Variables & Respondents n=741 \\
\hline Sex & $77(10 \%)$ \\
\hline Female & $658(89 \%)$ \\
\hline Male & $6(1 \%)$ \\
\hline Not reported & Mean 40.4, SD 11.7 \\
\hline Age (years) & Mean 11.9, SD 10.9 \\
\hline Work experience (years) & \\
\hline Mineworker occupation* & $285(38 \%)$ \\
\hline Miner labourers & $399(54 \%)$ \\
\hline Maintenance-technical staff & $55(7 \%)$ \\
\hline Supervisors-managers & $2(0 \%)$ \\
\hline Not reported & $86(12 \%)$ \\
\hline Extra rescue guide/medical training and responsibility \\
\hline Yes & $595(80 \%)$ \\
\hline No & $60(8 \%)$ \\
\hline Not reported &
\end{tabular}

*Mineworkers comprise miner labourers, maintenance-technical staff and supervisor managers. Miner labourers work with mineral processing. The maintenance-technical staff include electricians and machine operators. Supervisors-managers include all forms of supervisors and managers who work underground. ${ }^{30}$

\section{Sample}

Questionnaires ( $\mathrm{n}=1022)$ were distributed to seven participating mines between November 2016 and February 2017. The response rate was $73 \%(\mathrm{n}=741)$ after excluding 29 individuals who were not working underground and 11 individuals with missing data for more than one-fourth of the study variables. Table 1 presents the details of the participant characteristics.

\section{Questionnaire}

The study-specific questionnaire in Swedish was specifically designed and constructed based on a review of preparedness literature and covered three areas: current mining preparedness literature, likely scenarios in Swedish mines and Swedish regulations. Preparedness for emergencies includes the inclusion of mineworkers with the relevant skills and ability to undertake the necessary actions. ${ }^{1121}$ Relevant emergency scenarios in mineral and metalliferous mines include fires, vehicular incidents and rock-falls ${ }^{4}$; therefore, we focused on these scenarios in the questionnaire. Swedish workplace regulations stipulate that the workplace risks determine the number of employees that should be educated in first aid and the availability of appropriate first aid equipment, ${ }^{19}$ such as stretchers, bandages and fire extinguishers. ${ }^{922}$

The questionnaire was designed to capture data on the preparedness of the mineworkers as immediate responders of moderately or more severely injured peers (eg, fractures, concussion or more severe injuries) until they were rescued during emergencies. Thus, the 
questions focused on the mineworkers' self-perceived knowledge of injuries and first aid, their first aid training and equipment, and the presumed risks of mining incidents, particularly concerning fires, vehicular incidents and rock-falls. Answers to the questions were either yes/ no responses or scores rated on a five-point Likert scale. Table 2 shows the frequencies of responses of 741 mineworkers to the questions in the questionnaire before an imputation of the dataset was performed. The face validity of the questionnaire was tested on three mineworkers. The relevance and validity of the items and the questionnaire were discussed during several seminars in an iterative process by the research group.

\section{Data collection}

At the time of study data collection, Sweden had 14 mineral and metalliferous mines of which nine were underground mines. The research team contacted the mine managers of these nine underground mines. Written information about the study and the questionnaire was sent to the managers via email to obtain informed consent, and the main unions were notified about the study. Seven out of nine mine managers agreed to participate and were then sent paper questionnaires via regular post for all employed mineworkers who were working underground. The mine managers were responsible for the distribution and collection of the questionnaires. A letter was attached to each questionnaire to inform the mineworkers that their participation was voluntary and that, by completing the questionnaire, the respondents gave their informed consent for study participation.

At the time of this study, the seven mines employed between 18 and 290 mineworkers. These underground mineral and metalliferous mines were involved in mining zinc, lead, silver, copper, gold and tellurium through various methods, for example, with sublevel stoping at varying maximum depths of between 235 and $1500 \mathrm{~m}^{23}$

\section{Analysis}

Descriptive analysis and data management

First, a descriptive analysis of the data was performed, including frequencies, minimum and maximum, mean, $\mathrm{SD}$, skewness and kurtosis. The descriptive analysis indicated that all questions had less than $10 \%$ missing values. Imputation with an expectation-maximisation estimation was performed to impute the missing data of the variables included in the analysis. ${ }^{24}$

A significance level of 0.05 was used for all study analyses, and SPSS (IBM Corp, IBM SPSS statistics for Windows, V.24.0) was used to impute the data with an expectation maximisation estimation, and Stata (StataCorp LP, Stata statistical software: release 14) was used for all other analyses.

\section{Exploratory factor analysis}

Exploratory factor analysis was performed for data reduction purposes,${ }^{25}$ to generate relevant analyses of the mineworkers' preparedness based on a rich material, wherein most of the mineworkers had chosen the middle alternative of the Likert scale for the questions, which made it unclear how the data could fit into logistic regression models. Moreover, a decision to perform an exploratory factor analysis was made to identify latent factors that contribute to the covariance of the manifest variables. ${ }^{25}$ Moreover, this made it possible to construct relevant complementing emergency medical factors to the key areas constructed by the Mine Safety Technology and Training Commission. ${ }^{11}$ In the exploratory factor analysis, six factors had eigenvalues $>1$. However, when comparing the constructs and studying the resulting scree plot, a decision was made to retain three factors with an eigenvalue $>2$ due to the opportunity to form relevant and meaningful factors as well as the fact that the scree plot started to level out after three factors. The three retained factors were rotated using Promax, and a threshold of 0.5 was chosen for the factor loadings, where a value of 0.5 indicates a strong loading for the items. ${ }^{25}$ Therefore, items with a minimum loading of 0.5 from the first, second, and third factors were added together. The three-factor solution is shown in figure 1. Cronbach's alpha and average interitem correlations were derived for factors 1,2 and 3 as 0.86 and $0.41,0.87$ and 0.41 , and 0.80 and 0.37 , respectively.

The following three factors illustrate the mineworkers' medical peer response preparedness: (1) Familiarity with rescue procedures during emergencies with injuries, containing questions Q3, Q4a-Q4d and Q5a-Q5d; (2) Risk perception of emergencies with injuries, covering questions Q2, Q6a-Q6e and Q7a-Q7d and (3) Experience of using self-protective and first aid equipment containing questions covering Q1a stretcher, bandages, splints, eye rinse, defibrillators, self-contained selfrescuers and fire extinguishers.

\section{Multiple logistic regression analysis}

In the multiple logistic regression analysis, the three factors were used as independent variables and the question 'Do you consider yourself prepared to respond (before the EMS or rescue personnel arrive at the incident site) to emergencies, for example, fire, explosions or rock-falls in the mine?' was used as the global dependent variable. The postestimation tests of the Pearson $\chi^{2}$ goodness-of-fit test as well as the Hosmer-Lemeshow test were performed and had insignificant results, indicating a goodness of fit for the model. ${ }^{26}$

\section{Participant and public involvement statement}

Neither patients nor the public was included in the design, conduct, reporting or dissemination plans of the research. However, the questionnaire was tested for face validity from both, mining employer and employee, perspectives.

\section{RESULTS}

The three constructed factors illustrate the aspects of relevance for the mineworkers' medical peer firstresponse preparedness. Familiarity with rescue procedures during emergencies with injuries includes whether 


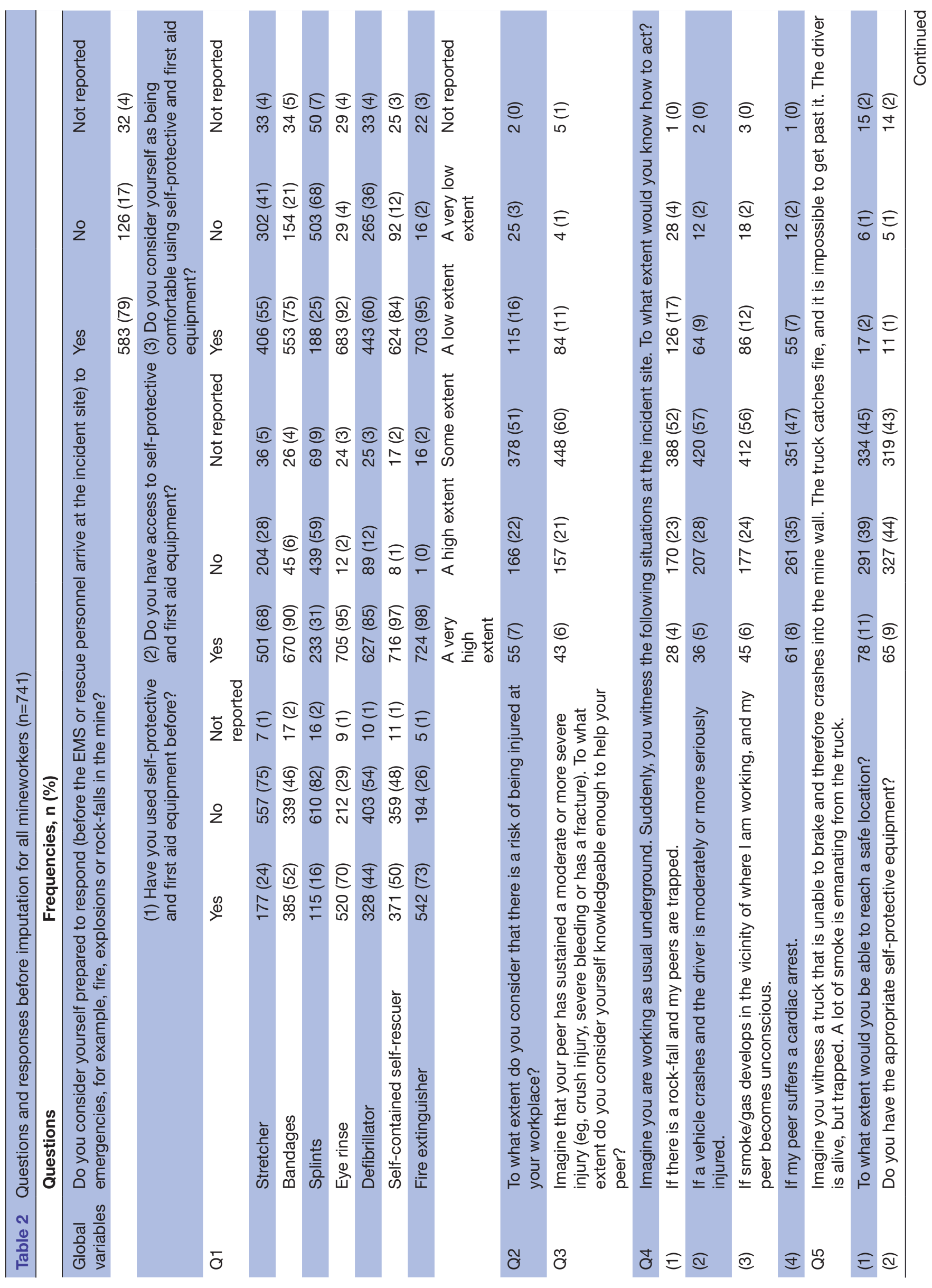




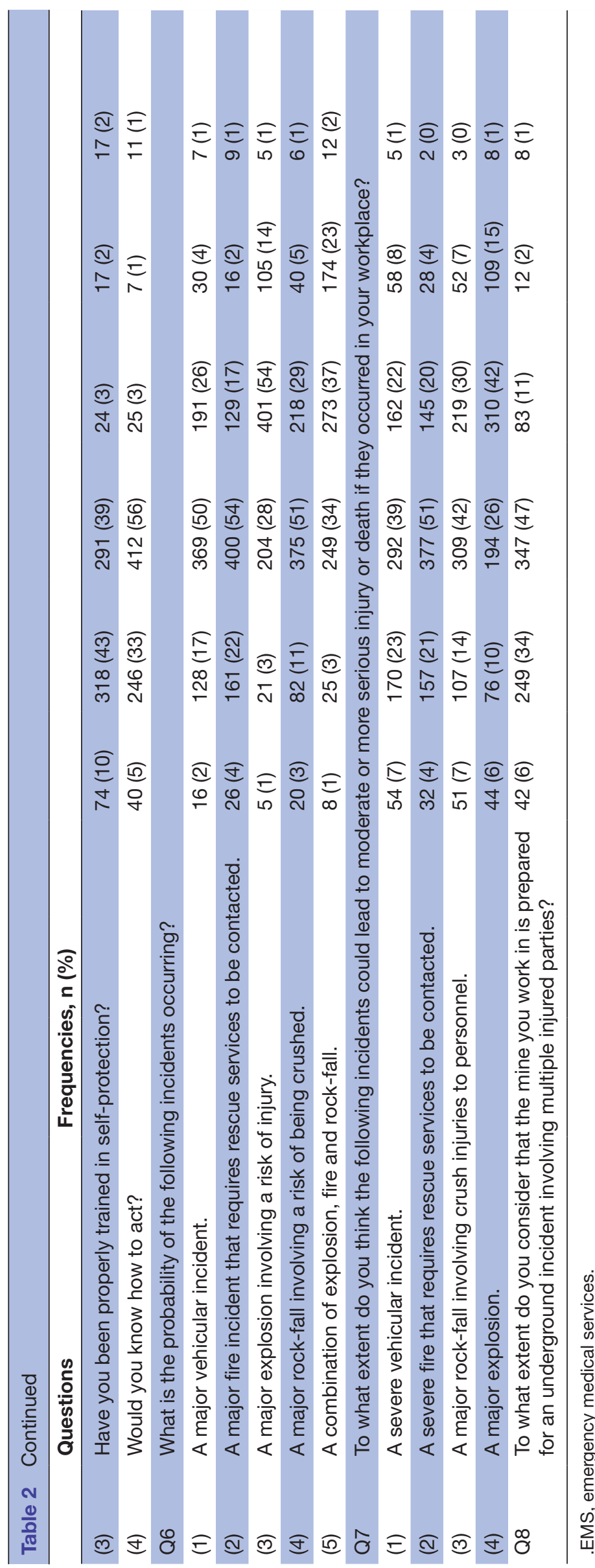


Factor loading

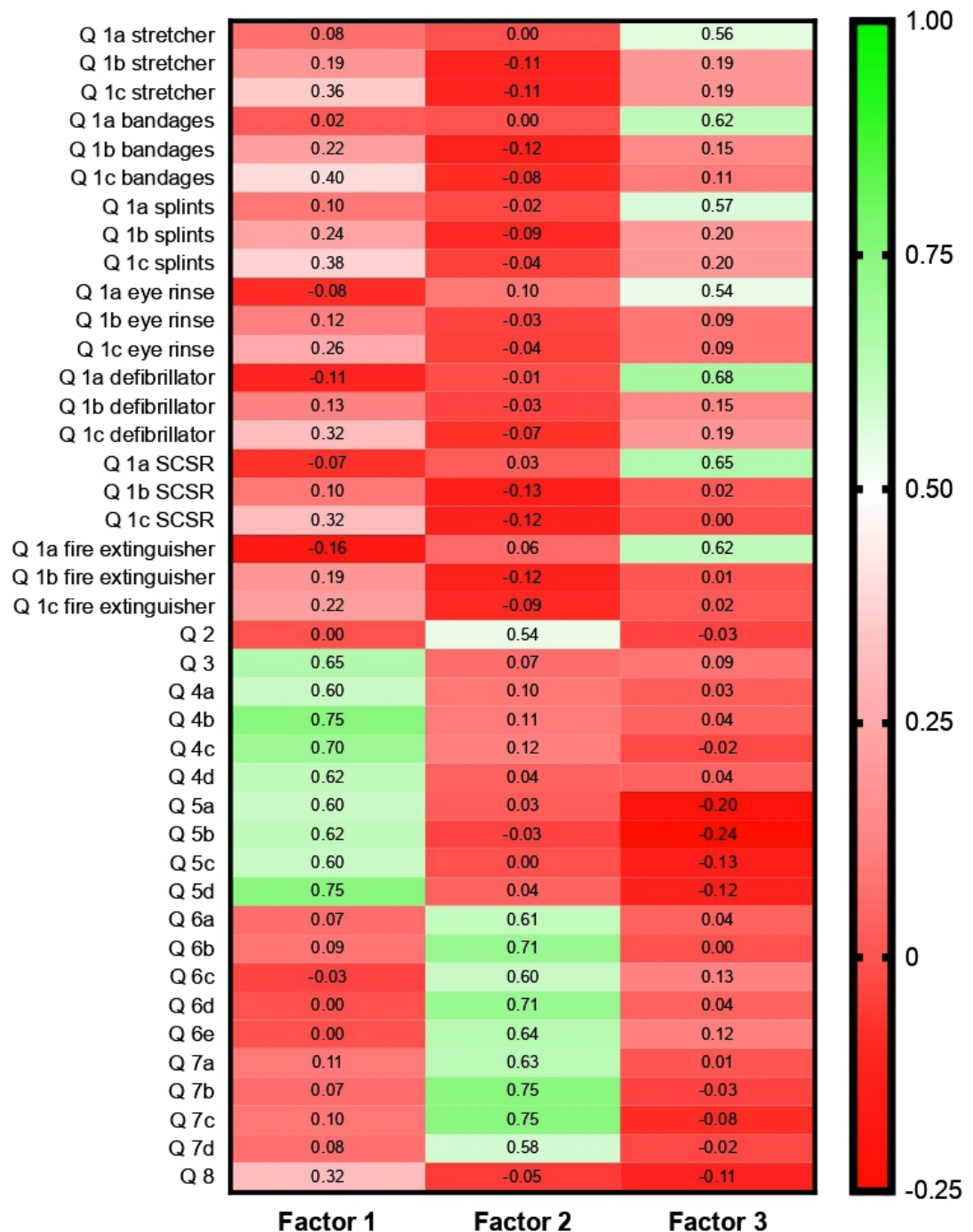

Unexplained variance

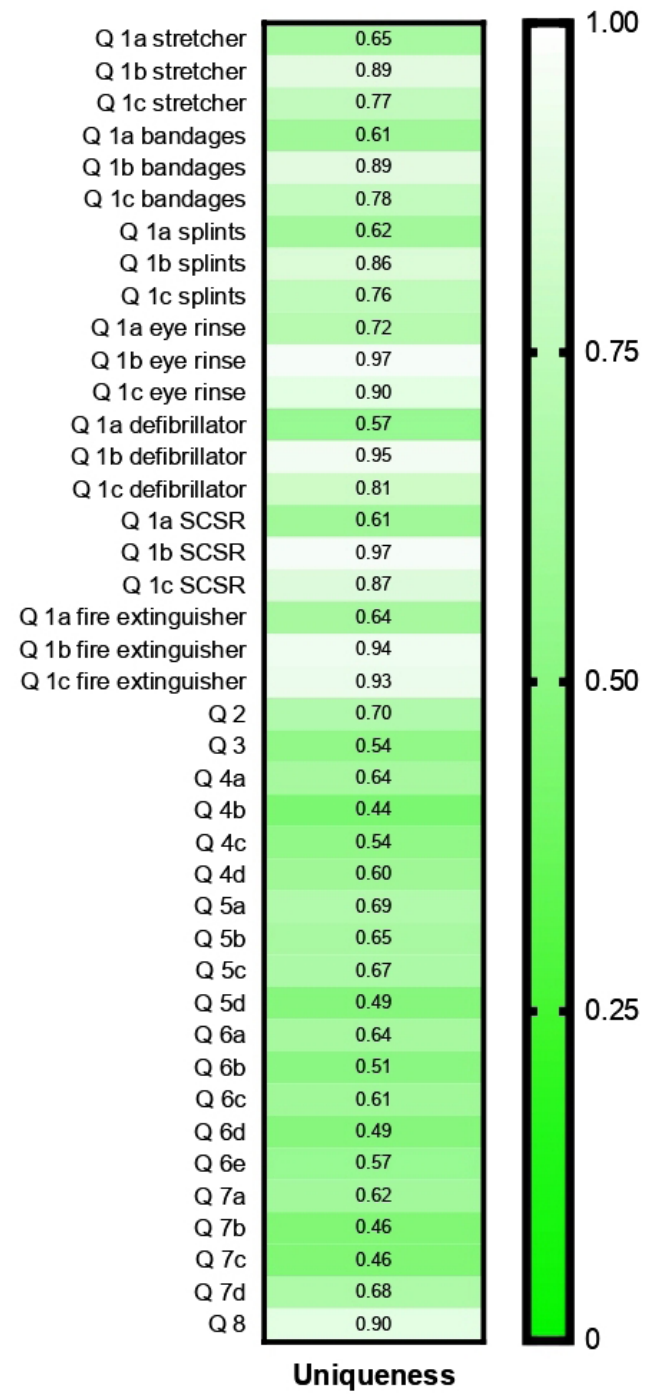

Figure 1 (A) Heatmap illustrating the loadings of the questions to the three factors, where 0.5 was the lower limit for being included in the respective factor and (B) Heatmap illustrating the unexplained variance of the questions to the three factors. SCSR, self-contained self-rescuer.

the mineworkers know how to act during stressful situations when there is an emergency, and a peer has been injured in the vicinity. Risk perception of emergencies with injuries includes how mineworkers interpret the perceived risk for emergencies with injuries at their workplace. Experience of using self-protective and first aid equipment includes aspects of whether the mineworkers have used/know how to use the equipment, such as a stretcher, bandages, splints, self-contained self-rescuers and fire extinguishers. There were significant associations between the three factors of preparedness and the global variable of self-reported preparedness. The associations between the factors and the global variable (figure 2) are further presented along with relevant highlights of how the 741 mineworkers answered the questionnaire (table 2).

Mineworkers familiar with rescue procedures during emergencies with injuries felt more prepared to respond before the rescue services and EMS arrived than those who were unfamiliar with the rescue procedures (OR $1.30,95 \%$ CI 1.22 to 1.38 ). As many as $79 \%$ of the 741 mineworkers considered themselves prepared to respond in the event of an emergency. For example, the mineworkers considered that they, to a high or very high extent, would know how to act if the driver is moderately or more seriously injured when a vehicle crashes (33\%), or when a vehicle catches fire $(38 \%$, and an additional $56 \%$ would to some extent, know what to do). Almost all $(91 \%)$ respondents reported that they had received first aid training, and $22 \%$ had experience in helping an injured peer. However, if a peer was moderately or more severely injured, only $27 \%$ considered themselves, to a high or very high extent, of being able to help. Nearly two-thirds $(60 \%)$ of the mineworkers thought that they, to some extent, knew how to provide a peer first aid response and help a moderately or more severely injured 


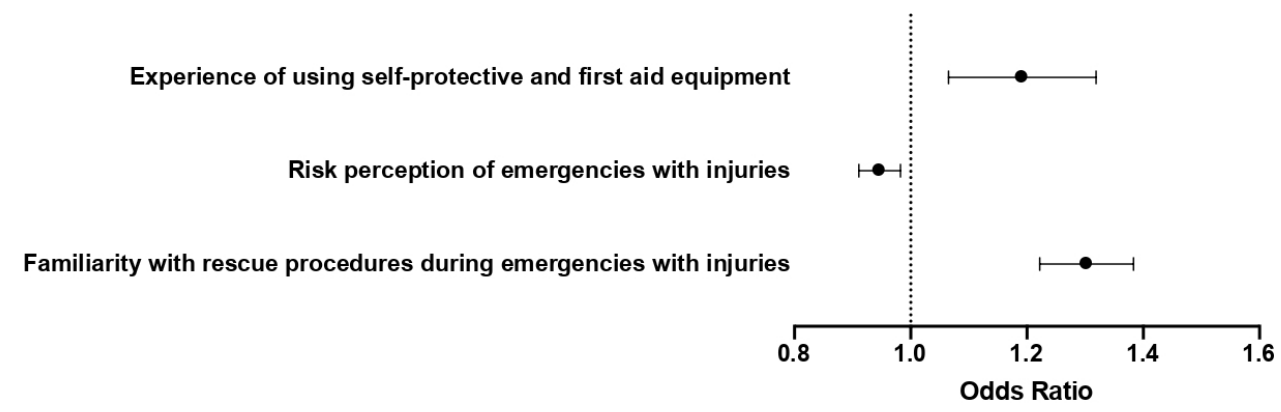

Figure 2 ORs and 95\% Cls showing the association between the three factors and the global variable of self-assessed preparedness to act before the rescue service and EMS arrive. EMS, emergency medical service.

peer, whereas $43 \%$ of the mineworkers knew, to a very high or high extent, how to act if a peer would suffer a cardiac arrest.

Mineworkers who considered that there was a great risk of emergencies with injuries believed themselves to be less prepared to respond than those who considered that there was a low risk of incidents (OR 0.95, 95\% CI 0.91 to 0.98 ). Overall, $80 \%$ of the mineworkers considered the risk of injuring themselves at their workplace to be moderate to very high. However, most mineworkers $(87 \%)$ believed that their mine was prepared for an underground incident involving multiple injured mineworkers, with moderate to very high degree of injury severity. When asked what kind of major incident scenarios they thought were likely, $80 \%$ of the mineworkers considered that the risk of a major fire incident that would require the rescue service to be contacted was moderate to very high. Onefourth $(25 \%)$ of the mineworkers believed that there was a high or very high risk for moderate or more serious injury during major fire incidents. Although major fires were considered probable, explosions were not considered to be as likely; $68 \%$ of the mineworkers imputed a low or very low risk of major explosions involving injury, and $57 \%$ thought there was a low or very low risk of major explosions leading to moderate or more serious injury or death.

Mineworkers with experience using their self-protective and first aid equipment were more prone to respond than those without this experience (OR 1.19, 95\% CI 1.07 to 1.32 ). In order to help injured peers, workers have to have knowledge in, access to and confidence in using several different kinds of self-protective and first aid equipment; to mention a few, $68 \%$ had access to a stretcher, about one-fourth $(24 \%)$ of the mineworkers had used one, and $55 \%$ considered themselves comfortable using stretchers. Seventy-five per cent of the mineworkers considered themselves to be comfortable using bandages and $25 \%$ were comfortable using splints; $85 \%$ of the mineworkers had access to a defibrillator, $44 \%$ had used one and $60 \%$ considered themselves comfortable using a defibrillator. Moreover, $73 \%$ of the mineworkers had used a fire extinguisher, and almost all (95\%) felt comfortable using it.

\section{DISCUSSION}

This study resulted in the identification of three factors: (1) Familiarity with rescue procedures during emergencies with injuries, (2) risk perception of emergencies with injuries and (3) experience of using self-protective and first aid equipment, which were of importance for mineworkers' perceived level of preparedness for emergencies resulting in injuries. These three factors have an emergency medical dimension with regard to the scenarios, including preparedness for taking care of injured mineworkers. Thus, the three identified factors can be viewed as being complementary to the three factors identified by the Mine Safety Technology and Training Commission for mineworkers to be able to self-escape or be rescued during emergencies in underground mines. ${ }^{11}$

The first factor of this study indicated that mineworkers familiar with rescue procedures considered themselves to be more prepared to respond to incidents before the rescue services and EMS arrived than those who were unfamiliar with the rescue procedures. In this study, the mineworkers were asked if they knew how to act in several difficult situations involving an injured peer (table 2). Although the mineworkers generally considered themselves prepared to respond $(79 \%)$, their answers indicated that certain scenarios could prove difficult. For example, the mineworkers were somewhat confident in what they should do if the driver is moderately or more seriously injured when a vehicle crashes $(57 \%)$, or when a vehicle catches fire $(56 \%)$. Their ability to respond during such stressful situations included making sound decisions and judgements. ${ }^{27}$ Prior training or experience of incidents have been shown to result in a better state of preparedness and to influence action during infrequent incidents that cause severe consequences. ${ }^{3}$ For example, those with prior experience of escaping from a smokefilled mine reported feeling less stress during an exercise under similar conditions, whereas mineworkers lacking this experience generally acted more on intuition than prior knowledge. ${ }^{28}$ As in this study, training mineworkers in their emergency skills has been shown to increase their preparedness for handling emergencies. ${ }^{27}$ However, the efficacy of self-escape training in communication, collaboration, leadership development, responsibility and accountability may be limited due to both structural and 
individual factors. ${ }^{29}$ Another study ${ }^{30}$ reported that mineworkers responding to dilemmas about critical self-rescue and escape skills did not always choose the safest option, though they understood the consequences of their choices. Two difficult dilemmas of that study included (1) leaving an injured mineworker behind and (2) trying to rescue missing mineworkers during unsafe conditions. ${ }^{30}$ Because mineworkers often respond to emergencies as a group,${ }^{11}$ they have to make optimal decisions for the whole group to escape. Training mineworkers to collaboratively make decisions and self-escape in simulated smoke may improve their ability to escape. ${ }^{11}$ Thus, based on the results of this study, training the mineworkers in the appropriate responses may improve their preparedness to act if their peers are injured. Their training may include table-top exercises, where the mineworkers can discuss different dilemmas and best practices when handling injuries, focused training on how to perform a procedure and full-scale scenario training.

The second factor in this study indicated that mineworkers who considered that there was a significant risk of emergencies with injuries assessed themselves as being less prepared to act before the rescue service and EMS arrived than those who considered that there was a low risk. Thus, this is perhaps a contradiction to another study, ${ }^{31}$ which reported that people with more experience and education of disasters and emergencies perceive a higher risk of emergencies, and therefore, are more prepared for new emergencies. In this study, 29\% and $51 \%$ of the mineworkers considered that there was a high or very high risk and moderate risk of sustaining workplace injuries, respectively. Furthermore, mineworkers considered that major fires were likely to occur, whereas uncontrolled explosions were not. The risk of the Swedish mineworkers sustaining a workplace injury has substantially decreased during the past 30 years, from 50.3 incidents per 1 million working hours to 7.1 in 2015 , because of investments in both technological development and in organisational measures (eg, the initiative of 'Safety First'). ${ }^{32}$ The Swedish mining companies are required, according to the Civil Protection Act, ${ }^{33}$ to be prepared for emergencies, which can occur even though relevant preventative measures have been implemented. ${ }^{9}$ The Swedish mines, for example, use an emergency plan of action until the rescue service personnel arrive, ${ }^{34}$ because, despite being uncommon, emergencies may include a risk to the life and health of the mineworkers. ${ }^{1}$ Examples of major Swedish incidents include a major fire incident in $2013,{ }^{35}$ and rock-falls caused by seismic events in the mine in $2020 .{ }^{36}$ The safety of mineworkers depends on their knowledge and ability to recognise and respond to hazards, and that might be influenced by training and experience. ${ }^{37}$ The Swedish mineworkers consider emergencies to be wake-up calls, and while the underlying problems are usually corrected, the mineworkers raise concerns about being trapped by a rock-fall or whether they could be rescued during major fires because of a complicated rescue operation. ${ }^{33}$ Thus, though objective measures prove the decreased frequency of incidents, several mineworkers believe that there exists a risk of emergencies that can lead to injury or death. The findings of this study indicate which of the emergency scenarios the mineworkers think are most likely, and thus a combination of prevention and preparedness strategies can be implemented to improve the mineworker's perception of the associated risks.

The third factor indicates that mineworkers with experience in using self-protective and first aid equipment, such as self-contained self-rescuers (50\%), bandages $(52 \%)$ or defibrillators (44\%), also considered themselves to be more prepared to respond during emergencies involving injuries. Hands-on training with first aid equipment improves layperson skills. ${ }^{38}$ Other authors have recommended that mineworkers practise using self-contained self-rescuers because, on several occasions, mineworkers have claimed that their equipment did not work in a real emergency. ${ }^{3}$ The equipment used during emergencies needs to be easy to use, even in highly stressful situations. ${ }^{8}$ To increase the preparedness of Swedish mineworkers, the mandatory annual evacuation training ${ }^{18}$ may preferably include the use of self-protective and first aid equipment. This supports the inclusion of practical training sessions in first aid courses, together with systematic training in the use of relevant self-protective and first aid equipment. Almost all of the mineworkers included in this study had been trained in first aid, as also reported from another Swedish study, ${ }^{33}$ which indicated that the mineworkers are trained to provide first aid and cardiopulmonary resuscitation and to use defibrillators. This means that the mineworkers have been educated in effective and safe techniques of first aid while using minimal or no equipment to provide initial care if a peer is injured or suffering from an acute illness. ${ }^{39}{ }^{40}$ Furthermore, educating mineworkers in first aid improves their confidence and likelihood of performing lifesaving first aid. ${ }^{41}$ However, current first aid courses generally do not cover trauma or mass-casualty situations ${ }^{42}$ or situations where professional help is far away. ${ }^{39}$ The majority of the mineworkers $(60 \%)$ believed that they, to some extent, would know how to help a severely injured peer. This might be due to the peers feeling of helplessness because they are unable to provide the appropriate level of care to the injured. ${ }^{17}$ For example, though $60 \%$ of the mineworkers in this study felt comfortable using a defibrillator for cardiopulmonary resuscitation, they may feel exposed and powerless. ${ }^{43}$ Other authors have shown that, in general, people tend to help injured people but may have low confidence in their first aid skills and training, with several other barriers for delivering first aid, for example, worry about making mistakes that could further harm the injured person. ${ }^{44-46}$ In line with our findings, training responders in first aid, as recommended by other authors, ${ }^{45} 46$ could improve their self-confidence and willingness to respond. The first aid training might focus on typical injuries and illnesses relevant to the underground environment. Training has been shown to increase the 
likelihood of optimal behaviour and decrease the risk of injury, ${ }^{47}$ but it needs to be context sensitive and consider the specific conditions in different mines, ${ }^{48}$ whereas providing each mineworker with sophisticated training in evacuation strategies. ${ }^{17}$ Thus, mining companies may consider this aspect, particularly as the onsite mineworkers are not only immediate responders, but some of them also have duties as guides for rescue services. ${ }^{33}$ Most of the mineworkers in this study attended regular first aid courses and, thus, the connection to the underground mining incident panorama might not have been evident. Moreover, in the first aid course, discussions of the psychological strain that emergencies with injuries could impose on the mineworkers could be included. These may be necessary for mineworkers to help a moderately or more severely injured peer in a rescue chamber for a long time before the arrival of rescue and emergency services. Therefore, modifying the first aid course to become more relevant to the mining context, including with regard to the psychological aspects, needs to be further explored.

\section{Limitations}

The strengths of this study include the fact that seven out of nine mines chose to participate. The response rate was high $(73 \%)$, which was adequate to assess the preparedness of the Swedish mineworkers. The decision to perform exploratory factor and multiple logistic regression analyses facilitated the analysis of a rich data material and the development of complementary factors associated with emergency medical preparedness to the key areas developed by the Mine Safety Technology and Training Commission. The multiple logistic regression analysis has insignificant post-estimation tests, indicating a suitable goodness of fit of the model.

Nonetheless, this study has some limitations. A drawback of the questionnaire was that most mineworkers chose the middle alternative of the Likert scale when answering the questions, which perhaps could have been counteracted by including another scale. The questionnaire itself was evaluated by the face validity of three mineworkers with vast experience of the mining environment in order to make the questions appropriate for the underground mine setting. Moreover, the questionnaire was discussed and improved iteratively by the research team before the questionnaires were sent out. However, a comprehensive pilot study might have improved the questionnaire further, as would a test/retest or random response test. Furthermore, this study analysed the selfassessed preparedness of mineworkers. More objective measures could have been obtained if a knowledge test or observations were performed on full-scale exercises. However, these were judged to be resource-intensive and beyond the scope of this study.

\section{CONCLUSIONS}

All mineworkers have to be readily prepared to act as immediate responders and care for their injured peers for a possibly extensive period until professional help arrives. We identified three factors important in the preparedness for peer support in underground mining environments. More research is needed to create evidence-based first aid courses that are adapted and contextualised to the needs of peer responders.

Acknowledgements The authors would like to express gratitude to the mining companies and workers involved in the research, especially those who helped develop the questionnaire. Furthermore, the authors are grateful to Dr Johan Svensson at the Umeå School of Business, Economics and Statistics for expert technical assistance with data analysis. We would like to thank Editage (www. editage.com) for English language editing.

Contributors The study was initiated, conceptualised and supervised by B-IS, UB, and LG. SK collected and analysed the data and drafted the manuscript. The manuscript was reviewed and revised by SK, BI-S, UB, MH and LG. All authors read and approved the final version of the manuscript.

Funding This work was supported by the Swedish National Board of Health and Welfare and the European Regional Development Fund under the project Safety \& Security Test Arena.

Competing interests None declared.

Patient and public involvement Patients and/or the public were not involved in the design, or conduct, or reporting, or dissemination plans of this research.

Patient consent for publication Not required.

Ethics approval The study was performed in accordance with the Declaration of Helsinki. The subject area and methods of this study were excluded from ethical vetting in accordance with the regulations of the Swedish Act concerning the Ethical Review of Research Involving Humans (SFS 2003:460); therefore, no ethical permission has been sought. Measures were taken to protect the anonymity and free will of the participants. The participating mines were sent paper questionnaires and information letters. The information letters informed the participants about the study and that participation was completely voluntary. Furthermore, they were informed that the results were to be presented at the group level, and no one would be able to identify individual answers. Although the participants were encouraged to answer all questions, they were free to hand in a blank or partially answered questionnaire. No sensitive personal information was collected. The participants provided their informed consent by anonymously answering the questionnaires. The participants were completely anonymised to the researchers as the data collection method made it impossible to create code lists.

Provenance and peer review Not commissioned; externally peer reviewed.

Data availability statement All data relevant to the study are included in the article or uploaded as online supplemental information. All data relevant to the study are included in the article.

Open access This is an open access article distributed in accordance with the Creative Commons Attribution Non Commercial (CC BY-NC 4.0) license, which permits others to distribute, remix, adapt, build upon this work non-commercially, and license their derivative works on different terms, provided the original work is properly cited, appropriate credit is given, any changes made indicated, and the use is non-commercial. See: http://creativecommons.org/licenses/by-nc/4.0/.

ORCID iD

Magnus Hultin http://orcid.org/0000-0003-2935-7161

\section{REFERENCES}

1 Bealko SB, Alexander DW, Chasko LL, et al. Mine rescue training facility inventory - compendium of ideas to improve US coal mine rescue training: The National Institute for Occupational Safety and Health (NIOSH). Trans Soc Min Metall Explor Inc 2011:517-24.

2 Enright C, Ferriter RL. Mine rescue manual: a comprehensive guide for mine rescue team members. Englewood, Colorado: Society for Mining, Metallurgy \& Exploration Inc.SME, 2014: 74-99.

3 Kowalski-Trakofler KM, Vaught C, Brnich MJ. Expectations training for miners using self-contained self-rescuers in escapes from underground coal mines. J Occup Environ Hyg 2008;5:671-7.

4 Engström KG, Angrén J, Björnstig U, et al. Mass casualty incidents in the underground mining industry: applying the Haddon matrix 
on an integrative literature review. Disaster Med Public Health Prep 2018:12:138-46.

5 Lehnen F. Mine rescue management: a concept for long-lasting missions based on case study analysis and disaster management approaches. Doctoral dissertation, Rheinisch-Westfälische Technische Hochschule Aachen, 2016.

6 Hansen R. Overview of fire and smoke spread in underground mines. Fourth International Symposium on tunnel safety and security, Frankfurt am Main, Germany 2010, 2010: 483-94.

7 Lehnen F, Martens PN, Rattman L. Evaluation of European mine rescue and its need for internationalisation. Fourth International Symposium mineral resources and mine development: 22-23 may 2013. Aachen international mining symposia. Germany: RWTH Aachen University, 2013: 175-86.

8 Brake R. An integrated strategy for emergency egress from an underground metal mine.University of Missouri, Rolla. Missouri: Eight US Mine Ventilation congress, 1999: 649-57.

9 Swedish Mining Industry's Health and Safety Committee. Brandskydd i gruv- och berganläggningar: Samlade råd och anvisningar.[Fire Safety in Mines and Underground Constructions. Stockholm: Swedish Association of Mines, Metal and Mineral Producers, 2016.

10 Conti RS. Responders to underground mine fires. Salt Lake City, Utah: Thirty-Second annual conference of the Institute on Mining Health, Safety and Research, 2001: 111-21.

11 Mine Safety Technology and Training Commission. Improving mine safety technology and training: establishing us global leadership. Washington DC: National Mining Association, 2006: 68-90.

12 Helsloot I, Ruitenberg A. Citizen response to disasters: a survey of literature and some practical implications. J Contingencies \& Crisis Man 2004;12:98-111.

13 Harris C, McCarthy K, Liu EL, et al. Expanding understanding of response roles: an examination of immediate and first responders in the United States. Int J Environ Res Public Health 2018:15:534.

14 Whittaker J, McLennan B, Handmer J. A review of informal volunteerism in emergencies and disasters: definition, opportunities and challenges. International Journal of Disaster Risk Reduction 2015;13:358-68.

15 Xiao T, Horberry T, Cliff D. Analysing mine emergency management needs: a cognitive work analysis approach. IJEM 2015;11:191-208.

16 Kitch C. Mourning "men joined in peril and purpose": working-class heroism in news repair of the sago miners' story. Crit Stud Media Commun 2007;24:115-31.

17 Kowalski-Trakofler KM, Vaught C. Psycho-Social issues in mine emergencies: the impact on the individual, the organization and the community. Minerals 2012;2:129-68.

18 Swedish Work Environment Authority. Berg- och gruvarbete: Arbetsmiljöverkets föreskrifter om berg- och gruvarbete samt allmänna råd om tillämpningen av föreskrifterna. [Mountain and mining quarrying: Swedish Work Environment Authority's legislation about mountain and mining quarrying and also general advice about the application of the legislation. Stockholm: Swedish Work Environment Authority, 2010.

19 Swedish Work Environment Authority. Första hjälpen och krisstöd: Arbetarskyddsstyrelsens föreskrifter om första hjälpen och krisstöd samt allmänna råd om tillämpningen av föreskrifterna. [First aid and social and psycological support: Swedish Work Environment Authority's regulations about first aid and social and psychological support and general advice on application of the regulations. Stockholm: Swedish Work Environment Authority, 1999.

20 Conti RS, Chasko LL, Wiehagen WJ, et al. Fire response preparedness for underground mines. Pittsburgh, PA: Centers for Disease Control and Prevention, National Institute for Occupational Safety and Health, 2005.

21 Slepski LA. Emergency preparedness: concept development for nursing practice. Nurs Clin North Am 2005;40:419-30. vii.

22 Walle M, Jennings N. Safety \& health in small-scale surface mines: $A$ handbook. 20. Geneva: International Labour Organization, 2001.

23 Geological Survey of Sweden. Bergverksstatistik 2019.Statistics of the Swedish mining industry. Uppsala: Geological Survey of Sweden, 2020.

24 Dong Y, Peng C-YJ. Principled missing data methods for researchers. SpringerPlus 2013;2:1-17.
25 Costello AB, Osborne JW. Best practices in exploratory factor analysis: four recommendations for getting the most from your analysis. Pract Assess Res Evaluation 2005;10:1-9.

26 StataCrop. Stata base reference manual - Release 14. College Station, Texas, USA: StataCorp LP, 2015.

27 Brnich MJ, Hall EE. Incorporating judgment and decisionmaking into quarterly mine escape training based on a mine fire scenario. Pittsburgh, PA: U.S: Department of Health and Human Services, Centers for Disease Control and Prevention, National Institute for Occupational Safety and Health, NIOSH, 2013: 1-16.

28 Kowalski-Trakofler KM, Vaught C, Scharf T. Judgment and decision making under stress: an overview for emergency managers. IJEM 2003:1:278-89.

29 Haas EJ, Hoebbel CL, Rost KA. An analysis of trainers' perspectives within an ecological framework: factors that influence mine safety training processes. Saf Health Work 2014;5:118-24.

30 Cole HP, Vaught C, Wiehagen WJ, et al. Decision making during a simulated mine fire escape. IEEE Trans Eng Manag 1998;45:153-62.

31 Mishra S, Suar D. Do lessons people learn determine disaster cognition and preparedness? Psychol Dev Soc J 2007;19:143-59.

32 Lööw J, Nygren M. Initiatives for increased safety in the Swedish mining industry: Studying 30 years of improved accident rates. Saf Sci 2019;117:437-46.

33 Swedish Code of Statutes. Lag (SFS 2003:778) om skydd mot olyckor. Civil Protection Act. Stockholm: Ministry of Justice, 2003.

34 Karlsson S, Gyllencreutz L, Engström G, et al. Preparedness for mining injury incidents - Interviews with Swedish rescuers. Safety Science Monitor 2017;20:1-10.

35 Marklund J, Haarala D. Fördjupad olycksundersökning gruvbrand 2013-08-25. [Incident investigation of fire in mine 2013-08-25] Skellefteå: Skellefteå Kommun, Räddningstjänsten, 2014: 1-29.

36 Luossavaara-Kiirunavaara AB. Sättningar i Kiruna den 18 maj. [Geological settings in Kiruna the 18 May] Luossavaara-Kiirunavaara AB, 2020. Available: https://www.lkab.com/sv/hallbarhet/miljo/ seismiska-handelser/seismiska-handelser-kiruna/sattningar-i-kirunaden-18-maj/ [Accessed 31 Jul 2020].

37 Kowalski-Trakofler KM, Vaught C, Brnich MJ, et al. A study of first moments in underground mine emergency response. J Homel Secur Emerg Manag 2010;7.

38 Goralnick E, Chaudhary MA, McCarty JC, et al. Effectiveness of instructional interventions for hemorrhage control readiness for laypersons in the public access and tourniquet training study (PATTS): a randomized clinical trial. JAMA Surg 2018;153:791-9.

39 Van de Velde S, Broos P, Van Bouwelen M, et al. European first aid guidelines. Resuscitation 2007;72:240-51.

40 Zideman DA, De Buck EDJ, Singletary EM, et al. European Resuscitation Council guidelines for resuscitation 2015 section 9. first aid. Resuscitation 2015;95:278-87.

41 Garcia EA, Likourezos A, Ramsay C, et al. Evaluation of emergency medicine community educational program. West J Emerg Med 2010;11:416-8.

42 Khorram-Manesh A, Plegas P, Högstedt Å, et al. Immediate response to major incidents: defining an immediate Responder! Eur J Trauma Emerg Surg 2019:1-12.

43 Axelsson A, Herlitz J, Fridlund B. How bystanders perceive their cardiopulmonary resuscitation intervention; a qualitative study. Resuscitation 2000;47:71-81.

44 Heard CL, Pearce JM, Rogers MB. Mapping the public first-aid training landscape: uptake, knowledge, confidence and willingness to deliver first aid in disasters/emergencies- a scoping review. Disasters 2019:1-77.

45 Ross EM, Redman TT, Mapp JG, et al. Stop the bleed: the effect of hemorrhage control education on laypersons' willingness to respond during a traumatic medical emergency. Prehosp Disaster Med 2018;33:127-32.

46 Riegel B, Mosesso VN, Birnbaum A, et al. Stress reactions and perceived difficulties of lay responders to a medical emergency. Resuscitation 2006;70:98-106.

47 Schouten R, Callahan MV, Bryant S. Community response to disaster: the role of the workplace. Harv Rev Psychiatry 2004;12:229-37.

48 Passmore D, Bennett J, Radomsky M, et al. Tailored safety training for miners in small Pennsylvania surface coal mines. Am J Public Health 1990;80:1134-5. 